\title{
UTILIZANDO A AUDIODESCRIÇÃO COMO UM RECURSO DE ENSINO
}

\author{
UTILIZANDO LA AUDIODESCRIPCIÓN COMO UN RECURSO DE \\ ENSEÑNANA
}

\section{USING AUDIODESCRIPTION AS A TEACHING RESOURCE}

\author{
Sabrina Gomes COZENDEY ${ }^{1}$ \\ Maria da Piedade Resende da COSTA ${ }^{2}$
}

\begin{abstract}
RESUMO: Este trabalho apresenta uma discussão sobre o uso da audiodescrição como um recurso de ensino nas aulas de física. $\mathrm{O}$ estudo tem como objetivo descrever, propor e analisar uma proposta de audiodescrição de um vídeo educativo. A pesquisa busca analisar o uso de um vídeo audiodescrito junto a alunos cegos, com baixa visão e videntes. Com base nos dados coletados é desenvolvida uma sequência didática para o ensino de conservação de energia. Os resultados mostram que a audiodescrição, além de ser um recurso de ensino importante para pessoas cegas e com baixa visão, pode facilitar a compreensão ou explicação de um conceito a alunos que não apresentam limitações visuais.
\end{abstract}

PALAVRAS-CHAVE: Ensino inclusivo. Audiodescrição. Recurso de ensino.

RESUMEN: Este trabajo presenta una discusión sobre el uso de la audiodescripción como un recurso de enseñanza en las clases de física. El estudio tiene como objetivo describir, proponer y analizar una propuesta de audiodescripción de un video educativo. La investigación busca analizar el uso de un vídeo audiodescrito junto a alumnos ciegos, con baja visión y videntes. Con base en los datos recolectados se desarrolla una secuencia didáctica para la enseñanza de conservación de energía. Los resultados muestran que la audiodescripción además de ser un recurso de enseñanza importante para personas ciegas y con baja visión, puede facilitar la comprensión o explicación de un concepto a los alumnos que no presentan limitaciones visuales.

PALABRAS CLAVE: Educación inclusiva. Audio descripción. Recurso de enseñanza.

ABSTRACT: This paper presents a discussion about the use of audio description as a teaching resource in physics classes. The study aims to describe, propose and analyze a proposed audio description of an educational video. The research seeks to analyze the use of audio description with blind and low vision students, and students who are not visually impaired. Based on the data collected, a didactic sequence for the teaching of energy conservation was developed. The results show that audiodescription, besides being an

${ }^{1}$ Universidade Federal de São Carlos (UFSCAR), São Carlos - SP - Brasil. Estágio de pós-doutorado. Doutora em Educação Especial. E-mail: sgcfisica@yahoo.com.br

${ }^{2}$ Universidade Federal de São Carlos (UFSCAR), São Carlos - SP - Brasil. Professora da Pós-graduação em Educação Especial. Departamento de psicologia. E-mail: piedade@ufscar.br 
important teaching resource for blind and low vision individuals, can facilitate the understanding or explanation of a concept to students who do not present visual limitations.

KEYWORDS: Inclusive education. Audio description. Teaching resource.

\section{Introdução}

Na Lei de Diretrizes e Bases da Educação Nacional (LDBEN) (BRASIL, 1996) é estabelecido o direito aos alunos com necessidades educacionais especiais (NEE) de acesso ao ensino especializado gratuito, preferencialmente na rede regular de ensino. Com esta determinação, as matrículas dos alunos com deficiência são asseguradas por lei. A LDBEN também prevê que para incluir adequadamente os alunos com necessidades educacionais especiais é preciso oferecer práticas e currículo adequados (BRASIL, 1996).

Para que um sistema educacional seja inclusivo, ele deve ser capaz de oferecer práticas e currículos adequados que possam garantir ao aluno alcançar uma aprendizagem adequada a cada série, isto independentemente se o aluno tenha ou não NEE.

Dentre os alunos que apresentam NEE estão os alunos com deficiência visual (DV). A DV é uma deficiência sensorial que abrange duas categorias: a de pessoas com baixa visão e a de pessoas com cegueira, estas últimas incluem as pessoas com cegueira congênita e com cegueira adquirida.

Um aluno com DV necessita de recursos educacionais que valorizem a audição e o tato, uma vez que não pode utilizar a visão como meio principal de acesso ao conhecimento.

Um recurso que pode ser utilizado como facilitador na mediação do processo de ensino e de aprendizagem em turmas que tenham alunos com DV é a audiodescrição (AD). A AD é uma modalidade de tradução que apresenta em linguagem oral o que é observado visualmente.

A $A D$ permite que pessoas com DV possam ouvir o que não pode ser visto em peças de teatro, no cinema, em exposições, em museus, por exemplo. Com a AD o visual se torna verbal (SNYDER, 2005).

Silva et al (2010) relatam que a AD é um serviço ou recurso cujo alvo são pessoas com DV e se caracteriza pela narração adicional de aspectos visuais da imagem, tais como: vestuário, linguagem corporal, aspectos da cena (quarto, parque, árvores, carros, 
semáforos), entre outros. A AD deve descrever de forma concisa e objetiva as imagens apresentadas.

Para Vieira e Lima (2010, p. 4), a AD pode ser classificada como uma:

Modalidade de tradução onde o que se pretende fazer é processar as informações permitindo a sua passagem de uma linguagem para a outra, procurando manter o maior nível de fidelidade entre o que está numa linguagem e o que é veiculado utilizando-se de outra.

Por causa de seu caráter inclusivo, no sentido de incluir a pessoa com cegueira, garantindo a esta compreensão do filme ou da série da TV, a AD é legalizada em vários países que exigem que os meios de comunicação a utilizem em seus programas (ARAÚJO, 2010).

No Brasil aos poucos a AD também ganha seu espaço. Segundo Vieira e Lima (2010), o direito das pessoas com deficiência terem acesso à audiodescrição é sustentado pela Lei $\mathrm{n}^{\circ} .10 .098$ (BRASIL, 2000) e no Decreto Legislativo $\mathrm{n}^{\circ}$. 186/2008 (BRASIL, 2008).

A Lei $\mathrm{n}^{\circ}$. 10.098, de 2000 (BRASIL, 2000), estabelece normas gerais e critérios básicos para a promoção da acessibilidade das pessoas com deficiência ou com mobilidade reduzida, e dá outras providências. No capítulo VII da referida Lei é estabelecido que o Poder Público:

Promoverá a eliminação de barreiras na comunicação e estabelecerá mecanismos e alternativas técnicas que tornem acessíveis os sistemas de comunicação e sinalização às pessoas portadoras dedeficiência sensorial e com dificuldade de comunicação, para garantir-lhes o direito de acesso à informação, à comunicação, ao trabalho, à educação, ao transporte, à cultura, ao esporte e ao lazer (BRASIL, 2000, p. 5).

Entendemos aqui o uso de imagens, vídeos, simulações e outros recursos visuais como uma barreira na comunicação de alunos com baixa visão ou alunos com cegueira. E assim, estes recursos precisam se tornar acessíveis ao alunos com deficiência visual.

No decreto Legislativo n. 186/2008, que aprova o texto da convenção sobre os Direitos das pessoas com deficiência e de seu Protocolo Facultativo, está previsto a garantia de que a educação de pessoas com cegueira seja ministrada nos modos e meios de comunicação mais adequados ao indivíduo (BRASIL, 2008). Novamente destaca-se que um recurso visual não é adequado ao indivíduo cego, este recurso precisa ser audiodescrito. 
Constatamos que muitos recursos de ensino são visuais como: vídeos, animações, simulações, experimentos, entre outros. Para que estes recursos sejam adequados ao ensino de pessoas com DV eles precisam ser audiodescritos. Mas como fazer a AD de um vídeo educativo?

Nesta pesquisa propomos uma estratégia para audiodescrever vídeos educativos. O presente estudo tem como objetivo descrever, propor e analisar uma proposta de AD de um vídeo educativo.

\section{Caracterização metodológica}

A presente pesquisa é qualitativa e descritiva caracterizada como estudo de caso. A coleta de dados foi realizada em ambiente natural. Conforme Bogdan e Biklen (1994), a ênfase está centrada no processo e tem a preocupação no entendimento dos participantes. Ao descrever a experiência, participa das decisões havendo a possibilidade de modificações.

Portanto, nos procedimentos metodológicos inicialmente foi realizada a descrição da proposta, seguida da análise da proposta e das etapas da pesquisa.

\section{Descrição da proposta}

Ao se produzir uma AD para o cinema ou para uma peça, as audiodescrições são preparadas para serem introduzidas nos intervalos entre as falas. Ou seja, a AD deve ser introduzida nos intervalos entre as falas dos atores. Contudo, quando uma peça ou filme é desenvolvido nem sempre há a preocupação de se deixar intervalos entre as falas para que a $\mathrm{AD}$ possa ser feita, o que em muitos casos inviabiliza a $\mathrm{AD}$ da obra.

Se o não planejamento da $\mathrm{AD}$ como parte da obra pode dificultar ou impedir que a AD seja realizada, como a AD poderia ser utilizada no ensino? A maior parte dos recursos educacionais não é desenhada pensando na possibilidade de um dia ser audiodescrita. Muitos vídeos educativos não têm intervalos entre as falas suficientes para que a AD possa ser realizada.

Um estudo desenvolvido por Camara e Espasa (2011) pode apresentar uma possível estratégia para audiodescrever vídeos educacionais que não tenham espaços suficientes entre as falas para que a AD seja realizada. No trabalho intitulado: "The Audio Description of Scientific Multimedia”, Camara e Espasa (2011) apresentam uma discussão sobre um 
estudo de caso: a audiodescrição do documentário "The Rhythms of Life". O documentário foi audiodescrito em espanhol para os membros da Organização Nacional de Cegos Espanhóis (ONCE). O documentário de 1995 foi audiodescrito em 1997, e uma das características mais marcantes da $\mathrm{AD}$ realizada para este documentário foi que ela aumentou a duração do filme em 15 minutos, ou seja, o documentário que tinha 60 minutos ficou com 75 minutos. Isto ocorreu porque no início do documentário a tela é congelada para que informações relevantes fossem audiodescritas. Segundo os autores do trabalho o congelamento da tela para fazer a $\mathrm{AD}$ não ocasionou problemas de sincronia, pois foi apresentado somente a pessoas cegas. Assim, esta técnica só pôde ser utilizada porque o documentário não foi utilizado no cinema, se assim o fosse, seria impossível congelar as imagens para fazer a $\mathrm{AD}$, pois acarretaria um problema de sincronização que poderia ser incômodo a pessoas videntes.

Camara e Espasa (2011) apontam uma possibilidade para fazer a AD quando não existem intervalos entre as falas dos atores. Contudo, segundo os autores, o congelamento da tela para fazer a AD só seria viável se o vídeo fosse utilizado somente com pessoas cegas.

Assim, a proposta apresentada no trabalho de Camara e Espasa (2011) para audiodescrever um vídeo não resolveria o problema de desenvolver a $\mathrm{AD}$ em vídeos educativos, uma vez que estamos pensando em uma proposta de ensino inclusiva, em que alunos com e sem DV possam aprender juntos. Desta forma, seria necessário criar vídeos com AD que pudessem ser utilizados com todos os alunos.

Como consequência das questões formuladas anteriormente e considerando o trabalho de Camara e Espasa (2011), propomos uma forma diferenciada de fazer a AD de vídeos educativos. Utilizamos a proposta de fazer a $\mathrm{AD}$ em momentos em que a tela é congelada para audiodescrever um vídeo de ensino de Física. A grande diferença do trabalho realizado na Espanha para o que realizamos é que o nosso recurso educativo foi desenvolvido para ser utilizado em sala de aula, com alunos com e sem deficiência visual. No caso espanhol eles apenas utilizaram o documentário com pessoas cegas. E a AD feita na tela congelada pelo grupo espanhol aconteceu no início do vídeo, para antecipar as informações importantes sobre o documentário. No caso deste trabalho as audiodescrições foram realizadas ao longo do vídeo, e assim a tela foi congelada algumas vezes.

Foi escolhido o vídeo "Os Curiosos - Trabalho e Potência", desenvolvido pelo Instituto Brasileiro de Educação e Tecnologia de Formação a Distância (IBTF), disponíveis 
no Portal do Professor do Ministério da Educação (http://portaldoprofessor.mec.gov.br/recursos.html) para ser audiodescrito. O vídeo foi escolhido por apresentar uma explicação do conceito de Física relacionando-o com situações cotidianas dos estudantes, e por apresentar elementos que só podem ser compreendidos visualmente, e outros que poderiam ser entendidos por pessoas cegas e pessoas com baixa visão. Assim, esse vídeo apresenta elementos que favorecem a análise da AD.

No quadro 1 é apresentada a sinopse do vídeo.

Quadro 1: Sinopse do vídeo

Sinopse do vídeo "Os Curiosos - Trabalho e Potência":
Essa atividade irá abordar o tema "trabalho e potência".
Primeiramente o professor explica o conceito de trabalho. Para auxiliar
a compreensão do conceito de trabalho é apresentada na tela uma imagem em
que há uma pessoa sentada em uma cadeira, uma caixa no chão e uma mesa,
na parede há um objeto que parece um relógio (mas não é). Esse objeto é
redondo como um relógio, possui um único ponteiro que fica apontado para
baixo, quando a pessoa da imagem levanta, senta, ou pega a caixa no chão, o
ponteiro desse objeto oscila para que a pessoa vidente possa perceber que
nesta ocasião houve trabalho.
Os conceitos de trabalho e o de potência são discutidos e apresentados
na forma desafios propostos a duas equipes de estudantes, a preto e a
vermelho.
A equipe vermelha realizará uma demonstração onde irão produzir
corrente elétrica com auxílio de uma bicicleta e de um dínamo. Ao pedalar a
bicicleta, o deslocamento da roda irá acionar o dínamo que irá produzir uma
corrente elétrica responsável por acender uma lâmpada (IBTF, 2010).
A equipe preta realizará uma demonstração onde dois estudantes
levantarão alguns pesos com auxílio de cordas realizando um trabalho. No
(IBTF, 2010).

Fonte: elaborado pelas autoras 
A AD do filme "Os curiosos: Trabalho e potência" foi centrada na ação, ou seja, foram audiodescritas as ações dos personagens e não aspectos físicos e vestimentas. Como o objetivo do vídeo é explicar um conceito, a ação realizada no filme é a parte mais importante, a parte que precisa ser audiodescrita para que o aluno com DV possa compreender o conceito. As vestimentas e os aspectos físicos dos personagens não influenciam na compreensão do conceito e assim não há uma necessidade de audiodescrever estes aspectos. É preciso considerar que a AD deve descrever somente o que é indispensável para a compreensão do vídeo, que neste caso tem como objetivo mediar compreensão de um conceito. Se todos os elementos do vídeo forem audiodescritos, ele se tornará desagradável a uma pessoa vidente.

Com a AD feita em momentos em que a tela foi congelada, o filme "Os Curiosos Trabalho e Potência" ganhou alguns minutos a mais: o filme original tinha 7:57 minutos e o filme audiodescrito ficou com 10:24 minutos, ou seja, com 2:27 minutos a mais.

Destaca-se que na $\mathrm{AD}$ da primeira parte do vídeo o objeto parecido com um relógio que indicava quando ocorria e quando não ocorria trabalho foi audiodescrito como um indicador de trabalho.

Para desenvolver a AD foi utilizado o software Audacity 1.3.12-beta para gravar a segunda faixa de áudio a ser acrescentada no filme. A edição do filme, momento em que as faixas de áudio correspondente às audiodescrições e aos textos informativos foram acrescentados ao filme, foi desenvolvida no software Corel Vídeo Studio 12.

Uma vez desenvolvido a AD do vídeo educativo, o recurso foi utilizado com alunos com e sem DV.

\section{Análise da proposta}

Em um primeiro momento buscamos analisar a proposta de desenvolver uma $\mathrm{AD}$ em uma tela congelada, e se a AD ajudava a compreender o conceito apresentado no vídeo. Esta análise foi desenvolvida em três etapas: 1) em centros de apoio pedagógico, em que 12 alunos cegos e dois com baixa visão avaliaram a proposta da AD; 2) em uma turma de Educação do Jovem e Adulta (EJA), em que 12 alunos, sendo um com baixa visão, avaliaram o uso do vídeo com AD em uma aula de ciências; 3) em uma turma de Ensino Médio, em que 12 alunos do segundo ano analisaram uma aula teste utilizando o recurso audiodescrito. 
A pesquisa foi aprovada pelo Comitê de Ética (parecer $n^{\circ}$. 08829613.8.0000.5504). Todos os participantes da pesquisa assinaram o termo de Consentimento Livre e Esclarecido (TCLE), e todas as atividades desenvolvidas foram gravadas para facilitar a posterior análise. Os dados coletados ao analisar o recurso audiodescrito foram utilizados como base para o desenvolvimento da sequência didática desenvolvida para ensinar o conceito de Conservação de Energia (Apêndice 1).

\section{Etapas de pesquisa}

1) Etapa em centros de Apoio Pedagógico

Buscando avaliar as potencialidades da AD desenvolvida como facilitadora da compreensão dos conceitos de Física, na primeira etapa da pesquisa foi desenvolvida uma estratégia para apresentar o vídeo a alunos cegos e alunos com baixa visão.

Foram desenvolvidas sessões de apresentação e discussão do vídeo audiodescrito em duas instituições de ensino públicas que oferecem apoio pedagógico especializado para alunos cegos e alunos com baixa visão. Participaram desta etapa da pesquisa 12 pessoas cegas e duas pessoas com baixa visão. Dentre estes alunos dois eram cegos congênitos.

As sessões foram desenvolvidas visando avaliar a audiodescrição proposta e para isso buscamos verificar se os participantes compreendiam o que estava sendo audiodescrito, se a audiodescrição estava clara, se era necessária mais informação, se alguma informação poderia ser desnecessária, se a forma como a audiodescrição foi feita (congelando a imagem quando o intervalo entre as falas era muito pequeno) seria bem aceita pelos alunos. Além disso, buscamos avaliar se esta audiodescrição cumpria com sua função que era a de tornar verbal o que era apresentado na forma visual e de suma importância para a compreensão do conceito.

Para organizar estas sessões e ao final delas poder validar ou não o vídeo audiodescrito, foi desenvolvida uma proposta de apresentação do vídeo na qual ele seria apresentado a um grupo de pessoas, e a pessoas em separado. Haveria dois momentos de análise: um utilizando o vídeo sem a audiodescrição e outro momento em que o vídeo seria utilizado com a audiodescrição.

Para favorecer as análises, para alguns participantes seria apresentado primeiro o vídeo com a audiodescrição e em um segundo momento o vídeo sem a audiodescrição, e para outro grupo de participantes no primeiro momento seria apresentado o vídeo sem a 
audiodescrição e no segundo momento seria apresentado e discutido o vídeo com a audiodescrição.

Estas sessões foram gravadas para favorecer a análise posterior. Para organizar a análise dos dados foram criadas categorias de análise. Algumas destas categorias estavam relacionadas à compreensão do vídeo e ao formato da AD. Outras categorias surgiram no momento em que os dados foram transcritos, quando se pode perceber alguns elementos que influenciaram na compreensão da $\mathrm{AD}$. Estes elementos são: a $\mathrm{AD}$ de um objeto real, a AD de um objeto irreal, a memória visual e o barulho externo.

\section{2) Etapa em uma turma de EJA}

Na segunda etapa da pesquisa o recurso foi utilizado em uma turma da EJA. A turma da EJA possuía um aluno com baixa visão. No total, doze alunos participaram das duas aulas testes realizadas. Na primeira aula foi utilizado o vídeo sem $\mathrm{AD}$, e em uma segunda aula foi desenvolvida uma discussão utilizando o vídeo com AD.

\section{3) Etapa em uma turma de Ensino Médio}

$\mathrm{Na}$ terceira etapa de análise do vídeo junto a alunos videntes, o recurso foi utilizado em uma turma de segundo ano do ensino médio. Doze alunos participaram de uma aula que utilizou o vídeo com e sem $\mathrm{AD}$, além de discutir o conceito apresentado no vídeo, os alunos foram convidados a analisarem a proposta de usar um vídeo com AD como um recurso de ensino, algo que estes alunos nunca tinham observado.

\section{Resultados}

1) Etapa: Uso da $\mathrm{AD}$ com alunos cegos e alunos com baixa visão em centros de Apoio Pedagógico

Com as sessões de uso e análise do vídeo audiodescrito podemos perceber que o vídeo estava adequado para os alunos cegos e alunos com baixa visão. Como foram apresentados tanto o vídeo com $\mathrm{AD}$ como o vídeo sem a $\mathrm{AD}$, os alunos conseguiram fazer uma relação entre eles, e puderam perceber que não compreenderam muitas partes do vídeo sem a $\mathrm{AD}$. De forma geral, todos os participantes cegos e participantes com baixa visão da pesquisa compreenderam a explicação do vídeo e os elementos visuais quando foi utilizado o vídeo com $\mathrm{AD}$. 
Alguns alunos (10\%) que estavam acostumados a assistir filmes com $\mathrm{AD}$ perceberam a diferença da $\mathrm{AD}$ proposta. Segundo eles, evidentemente, a AD na tela congelada é diferente, contudo, cumpre a função de informar os elementos mais importantes para a compreensão do vídeo. Alguns alunos (45\%) até consideram a AD feita na tela congelada como melhor que a $\mathrm{AD}$ convencional, isto porque ela possibilitava saber exatamente o que estava sendo audiodescrito. Assim, alguns alunos (90\%) gostaram mais que outros (10\%), mas todos concordaram que a $\mathrm{AD}$ desenvolvida tornou o vídeo didático compreensível.

As discussões desenvolvidas com os alunos nos permitiram observar alguns elementos que influenciam na compreensão da AD. Estes elementos como antes citados são: a $\mathrm{AD}$ de um objeto real, a $\mathrm{AD}$ de um objeto irreal, a memória visual e o barulho externo.

$\mathrm{A} \mathrm{AD}$ de um objeto real refere-se à $\mathrm{AD}$ de qualquer coisa que exista no mundo real, por exemplo: uma cadeira, um guarda-chuva, uma bicicleta. Para que a AD seja compreensível é importante que o aluno conheça os objetos que estão sendo audiodescritos, se o aluno não conhece um ou mais elementos da $\mathrm{AD}$, possivelmente a $\mathrm{AD}$ não ajudará a compreender o que ocorre na cena. Assim, é preciso primeiro explicar os elementos presentes na cena para depois utilizar a AD.

A $\mathrm{AD}$ de um objeto irreal refere-se ao uso da $\mathrm{AD}$ para descrever uma representação que não existe na vida real. Em uma parte do vídeo havia uma animação em que uma pessoa levantava ou se sentava em uma cadeira, e pegava uma caixa que estava no chão. Durante a animação, um objeto presente no cenário da animação buscava representar a variação de trabalho conforme a ação da pessoa. Tal objeto, que na audiodescrição foi nomeado como "indicador de trabalho", não existe no mundo real. Portanto, trata-se de uma representação de um objeto irreal. Muitos alunos apresentaram dificuldades de compreender a $\mathrm{AD}$ deste objeto irreal, possivelmente por que esse objeto não fazia parte do cotidiano desses alunos. Como este tipo de representação é comumente utilizado no ensino de ciências exatas, a AD de objetos irreais precisa apresentar elementos que permitam ao aluno compreender a representação.

A memória visual refere-se à interferência da memória visual na compreensão da AD. Em alguns momentos a memória visual ajuda na compreensão da $\mathrm{AD}$, e o aluno aprende bem mais rápido o conceito. Mas em alguns momentos a memória visual faz com que o aluno interprete a $\mathrm{AD}$ de forma equivocada. Assim, o professor precisa prestar 
atenção no que o aluno compreende da $\mathrm{AD}$, se a compreensão não estiver adequada cabe ao professor informar o equívoco ao aluno.

O barulho externo refere-se às dificuldades de compreensão criadas pelo barulho externo. O barulho pode ser considerado um grande vilão para a AD. Se a AD for utilizada em um ambiente que tenha muitos ruídos ou conversas paralelas dificilmente alcançará bons resultados. $\mathrm{O}$ aluno precisa entender claramente a AD para que esta possa ajudá-lo a compreender o conceito discutido.

A seguir apresentamos algumas análises dos dados coletados:

-A AD de um objeto real

Quando a AD foi utilizada para descrever um objeto real, como, por exemplo: uma corda, uma mesa, uma caixa, uma bicicleta, um dínamo, etc., a descrição foi facilmente compreendida. Os participantes que conheciam os objetos que estavam sendo audiodescritos não apresentaram dificuldades em entender o que ocorria no vídeo.

Contudo, teve participante que, por exemplo, não sabia o que era um dínamo. Alunos que nunca tinham visto ou ouvido falar do dínamo tiveram muito mais dificuldades de compreender o conceito, sendo necessário fazer a $\mathrm{AD}$ da $\mathrm{AD}$, ou seja; foi necessário primeiramente audiodescrever o dínamo, o que era, como funcionava, para somente depois utilizar esse conhecimento para explicar o conceito de trabalho.

-A AD de um objeto irreal

$\mathrm{O}$ objeto irreal alvo da $\mathrm{AD}$ neste trabalho foi o indicador de trabalho. Não existe indicador de trabalho. Esse indicador de trabalho é uma representação criada para facilitar a compreensão do vídeo por pessoas videntes. A AD desse indicador foi necessária porque entender o que ocorria na imagem apresentada durante a fala do professor favoreceria a compreensão do conceito.

Em momentos em que o vídeo $\mathrm{AD}$ foi apresentado aos alunos muitos perguntaram: $\mathrm{O}$ que é um indicador de trabalho? Nesse momento foi necessário fazer a AD da AD. Somente depois de entender o que era um indicador de trabalho os alunos conseguiram compreender a explicação do conceito.

Esse objeto irreal passa despercebido para os alunos que assistiram ao vídeo sem a AD.

-A memória visual

A memória visual pode favorecer a compreensão do vídeo, seja ele com ou sem a $\mathrm{AD}$, mas também pode agir como um elemento dificultador da aprendizagem. 
Na segunda parte do vídeo a memória visual dos alunos os ajudou a compreender o conceito, pois, lembraram como o dínamo funcionava e assim ficou mais fácil compreender o conceito de trabalho.

Na terceira parte do vídeo a memória visual atrapalhou a compreensão do vídeo pelas pessoas que assistiram ao vídeo sem a AD. Quando os integrantes da equipe preta puxaram o peso para o segundo andar do prédio, os alunos entenderam que eles estavam puxando de baixo para cima com o auxílio de uma roldana, como muitas vezes os pedreiros fazem em obras. Só que o que ocorria era que dois integrantes da equipe preta puxavam do segundo andar de um prédio, com as mãos uma corda que tinha um peso preso na ponta. Nesta situação a memória visual dos alunos atrapalhou a compreensão do vídeo, contudo a compreensão do conceito pode ser preservada se o aluno pensar em uma roldana fixa, pois, na situação em que o peso é puxado de baixo para cima com o auxílio de uma roldana fixa a pessoa aplica uma força que gera um deslocamento, o que se caracteriza em trabalho, e como o tempo da ação é cronometrado é possível explicar o conceito de potência. Entretanto, os alunos que viram ao vídeo com $\mathrm{AD}$ apresentaram uma compreensão melhor do conceito de potência, pois entenderam de imediato que o peso estava sendo puxado do segundo andar sem auxílio de roldanas.

-O barulho

O barulho como um elemento dificultador da compreensão da $\mathrm{AD}$ pode ser observado nos trabalhos desenvolvidos com alguns alunos que assistiram ao vídeo sem fone de ouvido. Os alunos reclamaram que o barulho externo impediu que pudessem compreender algumas partes do vídeo. O barulho externo é um elemento que dificulta a compreensão do conceito, essa afirmação foi descrita por um dos alunos cegos. Segundo os participantes, a pessoa cega costuma a prestar a atenção em todos os elementos sonoros, assim se tiver muitos barulhos externos ou mesmo internos à sala de aula, este aluno prestará atenção a vários elementos sonoros e no final não vai compreender nenhum deles. É fato que o barulho atrapalha a atenção de todas as pessoas, mas como o aluno cego não pode utilizar a visão para compreender o mundo é muito mais prejudicado pelo barulho externo que os demais alunos.

\section{2) Etapa: Uso da AD- Turma da EJA}

Foram desenvolvidas duas aulas em uma turma de EJA que se intitulava como inclusiva, pois tinha um aluno com baixa visão. Com as discussões propostas nesta turma 
pode-se perceber como a $\mathrm{AD}$ pode incluir o aluno com baixa visão. $\mathrm{O}$ aluno incluído participou de toda a aula e ajudou a alguns colegas ensinando como era o funcionamento de um dínamo (que foi apresentado no vídeo).

$\mathrm{O}$ vídeo com $\mathrm{AD}$ foi uma novidade para todos os alunos, que se sentiram muito cômodos em avaliá-lo. Os alunos acharam o vídeo audiodescrito repetitivo, porém mais explicativo. Para os alunos da EJA o vídeo com AD estava melhor que o sem a AD, pois poderiam compreender melhor o conceito uma vez que ele era apresentado duas vezes. Quanto à formatação do vídeo não houve nenhum incômodo. Esta análise é positiva para pesquisa, pois mostra que o vídeo audiodescrito em momentos em que a tela é congelada pode ser utilizado em uma turma com alunos videntes.

\section{3) Etapa: Uso da AD em Turma de Ensino Médio}

Nas discussões realizadas com doze alunos do segundo ano do ensino médio, os estudantes apresentaram suas considerações em relação ao vídeo com AD. Primeiramente os alunos queriam saber o que estava acontecendo, porque o recurso didático era tão diferente.

Como a turma não tinha nenhum aluno com DV, os alunos acharam bem diferente a proposta, pois nunca tinham visto nada parecido. Eles não sabiam o que era $\mathrm{AD}$.

Alguns alunos (80\%) gostaram da proposta e disseram que aprenderam mais com o vídeo audiodescrito, outros (20\%) disseram que o vídeo era repetitivo. Nas discussões ficou claro que se o vídeo fosse muito demorado ele se tornaria cansativo e desmotivador.

Em uma análise quantitativa, $80 \%$ dos alunos gostaram mais do vídeo com AD e $20 \%$ preferiram ao vídeo sem $\mathrm{AD}$. Vale destacar que os alunos que preferiram ao vídeo sem AD disseram não se importar que o vídeo audiodescrito seja utilizado em sala de aula: se o vídeo não for muito demorado, não seria um incômodo.

\section{Sistematização de uma sequência didáticado uso da ad}

Uma vez que a $\mathrm{AD}$ feita em momentos em que a tela é congelada foi aprovada por alunos com e sem DV, foi organizada uma sequência didática para ensinar o conceito de Conservação de Energia.

Esta sequência foi elaborada para ser utilizada em uma turma de primeiro ano. Um professor do ensino médio, um professor de metodologia de ensino da Universidade Federal de São Carlos (UFSCar) e cinco alunos cegos participaram da elaboração da 
proposta da sistematização. A proposta passou por vários processos de reformulações até alcançar uma organização inclusiva, com potencial de ensinar alunos cegos, alunos com baixa visão e alunos sem necessidades educacionais especiais. A Sequência didática final está disponível no Apêndice 1.

A sequência didática foi aplicada junto a uma turma de primeiro ano de ensino médio que tinha um aluno cego incluído. Com a aplicação da sequência didática, percebemos que a $\mathrm{AD}$ pode ser utilizada no ensino de Física para pessoas com e sem deficiência visual. Todos os alunos tiveram condições de acompanhar a aula e tiveram autonomia para participar das discussões propostas.

Como já observado anteriormente, a AD mostrou ser um recurso de ensino que pode ser utilizada em todas as turmas. A AD auxilia na aprendizagem de todos os alunos.

\section{Considerações finais}

Primeiramente, pode-se perceber que a $\mathrm{AD}$ feita em momentos em que a tela é congelada pode alcançar os mesmos resultados que a AD convencional. Os alunos cegos e com baixa visão aprovaram a proposta, e conseguiram compreender um conceito apresentado em um vídeo que utilizou a distinta AD.

Segundo, pode-se dizer que a AD funciona como auxiliar no processo de ensino e de aprendizagem de conceitos de Física para pessoas com e sem DV. No entanto, a AD por si só não garante a compreensão do conceito, ou seja, o professor deve sempre estar atento para saber se o aluno compreendeu a $\mathrm{AD}$ ou se é necessário reforçar alguma informação.

Como observado na pesquisa, se o aluno não conhece um objeto apresentado na $\mathrm{AD}$, seja ele real ou irreal, a compreensão da AD fica prejudicada. A memória visual também pode levar o aluno a interpretar a AD de forma errônea, e cabe ao professor observar se o aluno compreendeu a explicação adequadamente.

$\mathrm{O}$ barulho externo também pode minimizar as potencialidades da $\mathrm{AD}$. Assim, não é possível dizer que ao utilizar um recurso audiodescrito em sala de aula os alunos compreenderão o conceito apresentado; algumas condições como as apresentadas anteriormente, precisam ser garantidas para que a $\mathrm{AD}$ possa auxiliar na compreensão do conceito. 
Com o uso do vídeo audiodescrito na turma inclusiva de EJA percebemos que o recurso pode ser utilizado em turmas inclusivas e todos os alunos podem aprender juntos, o conceito explicado.

Já o uso do vídeo audiodescrito com o grupo de alunos do ensino médio mostrou que o recurso pode ser utilizado em turmas regulares independente de ter um aluno com DV na turma. Contudo, alguns cuidados devem ser tomados, como: a $\mathrm{AD}$ não pode ser muito demorada, e o vídeo didático deve ser curto para garantir tempo para que este possa ser discutido.

A sequência didática desenvolvida com base nos dados coletados na pesquisa mostrou-se inclusiva, uma vez que possibilitou a participação de todos os alunos e contribuiu para que alunos com e sem DV aprendessem juntos.

A presente pesquisa trata sobre o uso da $\mathrm{AD}$ como recurso de ensino. E é assim que a $\mathrm{AD}$ deve ser enxergada, como um recurso de ensino que pode e deve ser utilizado em todas as turmas para todos os alunos. A AD precisa ser vista como um recurso para todos, e não como recurso que inclui alunos cegos e alunos com baixa visão. É claro que estes podem compreender muito mais se houver recursos com $\mathrm{AD}$, mas os outros alunos sem necessidades especiais também aprendem mais quando se utiliza um recurso com AD.

\section{REFERÊNCIAS}

ARAÚJO, V. L. Proposta Baseada em Pesquisa Acadêmica. In: MOTTA; L. M. V. M.; ROMEU FILHO, P. (Org.). São Paulo: Secretaria dos Direitos da Pessoa com Deficiência do Estado de São Paulo, 2010.

BOGDAN, R.; BRIKLEN, S. K. Investigação em educação: uma introdução à teoria a aos métodos. Portugal: Porto Editora, 1994.

BRASIL. Lei $\mathbf{N}^{\circ}$ 9.394, de 20 de dezembro de 1996. Disponível em: <http://www.planalto.gov.br/ccivil_03/Leis/L9394.htm>. Acesso em: 07 mar. 2011.

BRASIL. Lei Federal 10.098, de 19 de dezembro de 2000. Disponível em: <http://www.planalto.gov.br/ccivil_03/leis/L10098.htm>. Acesso em: 10 out. 2011.

BRASIL. Decreto Legislativo no 186, 2008. Disponível em: <http://www.planalto.gov.br/ccivil_03/congresso/DLG186-2008.htm>. Acesso em: 10 out. 2011.

CAMARA, L.; ESPASA, E. The Audio Description of Scientific Multimedia. In: TRANSLATOR, v. 17, ed. 2, p. 415-437, Edição especial: SI, 2011. 
IBTF. Instituto Brasileiro de Educação e Tecnologia de Formação a Distância. Projeto Acessa Física. Vídeo: Os Curiosos - Trabalho e Potência, 2010.

SILVA, F.; BONA, V.; SILVA, A.; CARVALHO, I.; SILVA, E. Reflexões sobre o pilar da áudio-descrição: "Descreva o que você vê". Revista Brasileira de Tradução Visual, v. $4, \mathrm{n}^{\circ} .4,2010$.

SNYDER, J. Audiodescription: The visual made verbal. In: International Congress Series, v. 1282, p. 935-939, 2005.

VIEIRA, P. A.; LIMA, F. A teoria na prática: áudio-descrição, uma inovação no material didático. Revista Brasileira de Tradução Visual, v. 2, edição 2, 2010.

\section{Como referenciar este artigo}

COZENDEY, Sabrina Gomes.; COSTA, Maria da Piedade Resende da. Utilizando a audiodescrição como um recurso de ensino. Revista Ibero Americana de Estudos em Educação, Araraquara, v. 13, n. 03, p. 1164-1186, jul./set., 2018. E-ISSN:1982-5587. DOI: $10.21723 /$ riaee.v13.n3.2018.9626

Submetido em: 29/03/2017

Revisões requeridas: 06/11/2017

Aprovado em: 20/12/2017 


\section{APÊNDICE 1}

\section{Conservação da energia mecânica}

\begin{tabular}{|l|}
\hline \multicolumn{1}{c}{ Princípios de design } \\
\hline \multicolumn{1}{|c|}{ Gerais } \\
\hline Perspectiva inclusiva: uma inclusão efetiva se dá quando os alunos com ou sem necessidades educacionais \\
especiais interagem e aprendem juntos, em meio à execução de um mesmo conjunto de atividades \\
(RODRIGUES, 2006). Logo, as atividades devem ser diversificadas e permitir a participação de todos os \\
alunos; \\
Deficiência visual e desenvolvimento: As pessoas com deficiência visual têm condições cognitivas de se \\
desenvolver tanto quanto as pessoas que não possuem a deficiência. Para que se dê o desenvolvimento, a \\
linguagem e os meios empregados na interação devem ser adequados à percepção das pessoas com deficiência \\
visual (VYGOTSKI, 1983). Assim, as atividades de ensino desenvolvidas em sala de aula devem explorar os \\
meios sensoriais que são acessíveis aos alunos com deficiência visual; \\
Vídeos educacionais e audiodescrição: os vídeos educacionais são ferramentas potenciais na apresentação \\
de conteúdos e como fomentadores de discussões (OROFINO, 2005). No caso do uso de vídeos com alunos \\
com deficiência visual, os vídeos podem ser audiodescritos. No entanto, na audiodescrição voltada para a \\
discussão de tópicos de ensino, deve-se buscar descrever não todas as ações e personagens, como é frequente \\
na audiodescrição voltada para o cinema (ARAÚJO, 2010), mas sim os objetos e ações que são relevantes em \\
relação ao conteúdo tratado (COZENDEY; COSTA, 2014a). Além disso, a audiodescrição para uso em sala \\
de aula pode envolver o congelamento de telas e não necessariamente precisa ocorrer ao mesmo tempo em \\
que são apresentadas as cenas (COZENDEY, COSTA; 2014b);
\end{tabular}

- Interação e atividade colaborativa: a aprendizagem pode ser potencializada por atividades que envolvam a interação social (VYGOSTKO, 1983). Neste sentido, as atividades, por exemplo aquelas baseadas no uso de vídeos audiodescritos, devem ocorrer de modo colaborativo, em que os alunos, em grupos, poderão buscar soluções e explicações para determinadas situações que se apresentam em sala de aula (COZENDEY, COSTA; 2014a);

\section{Específicos}

- Natureza fenomenológica do conhecimento específico: Os conceitos envolvidos na mecânica clássica se constroem como um conhecimento concreto-abstrato, que está relacionado como uma fenomenologia acessível aos sentidos (BACHELARD, 1996). No caso do conceito de energia da energia mecânica e sua conservação, ainda que sua percepção não seja direta, ela pode se dar a partir de fenômenos cotidianos. (DUIT, 2012). Logo, situações e objetos do cotidiano podem ser utilizados na atribuição de significado aos conceitos estudados;

- Concepções espontâneas: os alunos possuem concepções espontâneas sobre energia, bem caracterizadas na literatura, e que devem ser alvo de "tratamento" no processo de ensino e aprendizagem (CLEMENT, 1987; DUIT, 2012);

- Representações visuais e objetos irreais: Pela natureza abstrata dos conceitos de trabalho, energia e potência, não é incomum o uso de representações (gráficas), inclusive aquelas associadas a objetos irreais. Neste uso, as representações devem ser explicadas (COZENDEY, COSTA; 2014a).

\section{Referências}

- BACHELARD, G. La formation de l'ésprit scientifique: contribution a unepsychanalyse de Ia connaissance. Paris: LibrainePhilosophique J. Vrin, 1938. Tradução de Estela dos Santos Abreu. A formação do espírito científico: contribuição para uma psicanálise do conhecimento. Rio de Janeiro: Contraponto, 1996.

- CLEMENT, J. Overcoming students' misconceptions in physics: The role of anchoring intuitions and analogical validity. In: J. NOVAK (Ed.). Proceedings of the second international seminar misconceptions and educational strategies in science and mathematics, Ithaca, NY: Cornell University, V. III, pp. 84-96, 1987.

- COZENDEY, S. G.; COSTA, M. P. R. A Audiodescrição como um recurso de ensino no ensino dos conceitos de Trabalho e Potência. In: VI Congresso Brasileiro de Educação Especial, 2014, São Carlos. Anais do VI Congresso Brasileiro de Educação Especial. São Carlos: UFSCar, 2014a. v. 1. p. 1-16.

- COZENDEY, S. G.; COSTA, M. P. R. Procedimento para a construção de uma audiodescrição congelando a tela: Um estudo de caso para ensinar conceitos de Física. Revista Ibero-Americana de Estudos em Educação, v. 9, p. 782-803, 2014b.

- $\quad$ DUIT, R. Teaching and Learning the Physics Energy Concept. In: Energy Summit: Developing a framework for the teaching and learning of energy, 2012, Lansing.

- OROFINO, M.I. Mídias e mediação escolar: pedagogia dos meios, participação e visibilidade. São Paulo: Cortez: Instituto Paulo Freire, 2005. v.12.

- RODRIGUES, D. Dez idéias (mal)feitas sobre a educação inclusiva. In: (2006) David Rodrigues (Org.). Inclusão e Educação: doze olhares sobre a Educação Inclusiva, São Paulo. Summus Editorial, 2006, p.1-16.

- VYGOTSKI, L. V. OBRAS ESCOGIDAS V. Fundamentos de defectologia. Ed. Pedagógica, Moscú, 1983. 
Tema: Conservação da energia mecânica

Conteúdos disciplinares: Energia mecânica (cinética e potencial), Conservação da energia mecânica, Forças conservativas e não conservativas.

Público alvo: Alunos do $1^{\circ}$ ano do Ensino Médio.

Contexto (referência): A sequência de atividades foi elaborada considerando a realidade da escola pública do estado de São Paulo, e assumindo que houvesse a disponibilidade de um Datashow. As atividades são direcionadas a turma que possua, além de alunos sem necessidades educacionais especiais, alunos com deficiência visual.

\begin{tabular}{|c|c|c|c|}
\hline \multicolumn{4}{|c|}{ Descrição das Etapas } \\
\hline Etapa & Desenvolvimento & Recursos & $\begin{array}{l}\text { Duração } \\
\text { prevista }\end{array}$ \\
\hline 1 & $\begin{array}{l}\text { Motivação e levantamento de concepções } \\
\text { prévias: a etapa tem como objetivo efetuar um } \\
\text { levantamento das concepções dos alunos sobre } \\
\text { energia, e estabelecer associações entre energia } \\
\text { mecânica e movimento. } \\
\text { A Etapa se dividirá em } 3 \text { momentos: } \\
\text { Momento } 1 \text { (5 min.) - discussão conjunta sobre a } \\
\text { energia no cotidiano (Onde percebemos energia?); } \\
\text { Momento 2 (10 min.) - atividade individual em que } \\
\text { os alunos deverão separar tipos de energia que } \\
\text { identificam no cotidiano, com exemplos; } \\
\text { Momento } 3 \text { (5 min.) - nova discussão conjunta } \\
\text { baseada na atividade individual. }\end{array}$ & $\begin{array}{l}\text { Material com questões de apoio } \\
\text { para os momentos } 1 \text { e } 2 \text {, em que } \\
\text { os alunos registrarão suas } \\
\text { respostas. No caso do } \\
\text { questionamento envolvido no } \\
\text { momento 2, há uma tabela com } \\
\text { três colunas (Fonte de energia, } \\
\text { tipo de energia, fenômeno) e } \\
\text { várias linhas (Material 01). }\end{array}$ & $20 \mathrm{~min}$ \\
\hline 2 & $\begin{array}{l}\text { Introdução à relação entre energia e movimento } \\
\text { (Energia cinética): a etapa tem como objetivos } \\
\text { permitir estabelecer relações entre a energia e a } \\
\text { velocidade em um movimento, levando à } \\
\text { formalização do conceito de energia cinética. } \\
\text { A Etapa se dividirá em } 6 \text { momentos: } \\
\text { Momento } 1 \text { (5 min.) - comentários iniciais sobre a } \\
\text { relação entre energia e movimento (recapitulação), } \\
\text { e exposição de dois vídeos envolvendo movimento; } \\
\text { Momento } 2 \text { (5 min.) - discussão conjunta tendo } \\
\text { como base o questionamento "Em um movimento, } \\
\text { onde há energia?", que deve levar ao } \\
\text { reconhecimento de que é necessário um critério } \\
\text { mais claro para identificar a energia; } \\
\text { Momento } 3 \text { (15 min.) - Um terceiro vídeo é } \\
\text { apresentado, e com base nele os alunos, em grupo } \\
\text { com } 3 \text { ou } 4 \text { integrantes, devem discutir o que, } \\
\text { envolvido no movimento, poderia estar associado à } \\
\text { energia (Entre dois carros correndo, para qual } \\
\text { haverá mais energia relacionada ao movimento?); } \\
\text { Momento } 4 \text { (5 min.) - discussão conjunta com a } \\
\text { turma, a partir das possibilidades que elencaram em } \\
\text { grupo, no momento } 3 \text {. A discussão deve ser } \\
\text { encaminhada no sentido de reconhecer a velocidade } \\
\text { como associada a uma forma de energia; } \\
\text { Momento } 5 \text { ( } 40 \text { min.) - Formalização do conceito } \\
\text { de energia cinética e resolução de exercícios } \\
\text { algébricos, tendo como base um texto explicativo e } \\
\text { com atividades. Parte dos exercícios deverão ser } \\
\text { realizados pelos alunos. }\end{array}$ & $\begin{array}{l}\text { Momento 1: } \\
\text { Vídeo de uma corrida de } \\
\text { atletismo vencida pelo velocista } \\
\text { UsainBolt (Vídeo 01), um } \\
\text { segundo vídeo, audiodescrito, } \\
\text { com uma reportagem que trata da } \\
\text { velocidade que Bolt alcança em } \\
\text { suas corridas (Vídeo 02). } \\
\text { Momento 3: } \\
\text { Vídeo audiodescrito com o } \\
\text { movimento de dois carros em um } \\
\text { torneio de arrancadas, indicando a } \\
\text { velocidade destes em três } \\
\text { posições da pista (Vídeo 03). } \\
\text { Momentos 1 a 3: } \\
\text { Texto com questões de apoio às } \\
\text { discussões (Material } 02 \text { ) } \\
\text { Momento 4: } \\
\text { Texto explicativo sobre o } \\
\text { conceito de energia cinética e } \\
\text { com exercícios conceituais e } \\
\text { algébricos, sendo alguns baseados } \\
\text { nos movimentos representados } \\
\text { nos vídeos } 01,02 \text { e } 03 \text { (Material } \\
\text { 03). } \\
\text { Vídeos originais (não editados e } \\
\text { sem audiodescricão): }\end{array}$ & $\begin{array}{l}1 \mathrm{~h} \text { e } 20 \\
\text { min. }\end{array}$ \\
\hline
\end{tabular}




\begin{tabular}{|c|c|c|c|}
\hline & 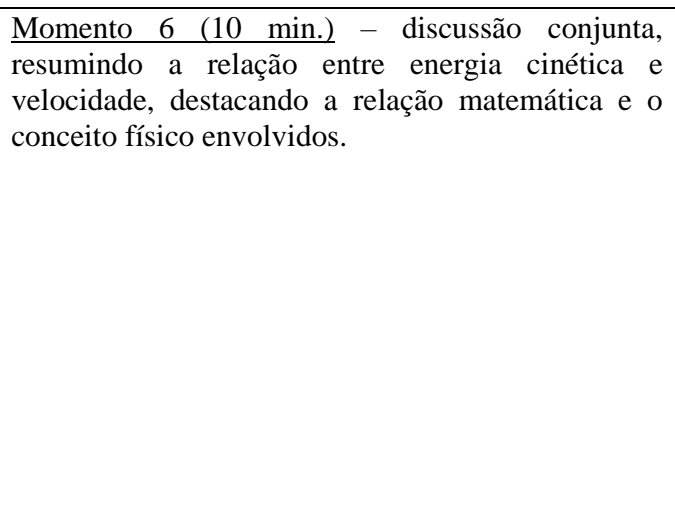 & $\begin{array}{l}\text { Video 01: } \\
\text { http://sportv.globo.com/olimpiada } \\
\text { s/videos/v/pilulas-olimpicas- } \\
\text { usain-bolt-ganha-medalha-de- } \\
\text { ouro-nos-100m-nas-olimpiadas- } \\
\text { de-londres/4972530/ } \\
\text { Vídeo 02: } \\
\text { https://www.youtube.com/watch? } \\
\text { v=3ZeJzuThzr0 } \\
\text { Video 03: } \\
\text { https://www.youtube.com/watch? } \\
\text { v=MdHVjYM9WsM }\end{array}$ & \\
\hline 3 & $\begin{array}{l}\text { Continuação da discussão sobre a relação entre } \\
\text { energia e movimento (Energia potencial): a etapa } \\
\text { tem como objetivos permitir estabelecer relações } \\
\text { entre a possibilidade de haver um movimento e a } \\
\text { altura, levando à formalização do conceito de } \\
\text { energia potencial gravitacional. } \\
\text { A Etapa se dividirá em } 5 \text { momentos: } \\
\text { Momento } 1 \text { (5 min.) - comentários iniciais sobre a } \\
\text { relação entre energia e velocidade, recapitulando o } \\
\text { conceito de energia cinética; } \\
\text { Momento } 2 \text { (10 min.) - a partir de um vídeo, e } \\
\text { reunidos em grupo com entre } 3 \text { e } 4 \text { integrantes, os } \\
\text { alunos deverão pensar no que leva um objeto em } \\
\text { queda livre a alcançar a maior velocidade, ou seja, } \\
\text { a uma maior energia cinética. } \\
\text { Momento } 3 \text { (5 min.) - discussão conjunta com a } \\
\text { turma, a partir das possibilidades que elencaram em } \\
\text { grupo, no momento } 2 \text {. A discussão deve ser } \\
\text { encaminhada no sentido de reconhecer a altura } \\
\text { como associada a um potencial de movimento e, } \\
\text { por consequência, a uma forma de energia; } \\
\text { Momento } 4 \text { (25 min.) - Formalização do conceito } \\
\text { de energia potencial e resolução de exercícios } \\
\text { algébricos. Parte dos exercícios deverão ser } \\
\text { realizados pelos alunos. } \\
\text { Momento } 5 \text { (5 min.) - discussão conjunta, } \\
\text { resumindo a relação entre energia potencial e } \\
\text { altura, destacando a relação matemática e o } \\
\text { conceito físico envolvidos. }\end{array}$ & $\begin{array}{l}\text { Momento 2: } \\
\text { Vídeo audiodescrito com um } \\
\text { movimento de queda livre com a } \\
\text { indicação do aumento da } \\
\text { velocidade na queda, da altura e } \\
\text { do tempo de queda (Vídeo 04). } \\
\text { Momentos 2 e 3: } \\
\text { Texto com questões de apoio às } \\
\text { discussões (Material 04) } \\
\text { Momento 4: } \\
\text { Texto explicativo sobre o } \\
\text { conceito de energia potencial e } \\
\text { com exercícios conceituais e } \\
\text { algébricos, sendo um deles } \\
\text { baseado no movimento } \\
\text { apresentado no vídeo } 04 \\
\text { (Material 05) } \\
\text { Vídeo original (não editado e sem } \\
\text { audiodescrição): } \\
\text { Vídeo 04: } \\
\text { http://canaloff.globo.com/progra } \\
\text { mas/ultimas- } \\
\text { do/materias/brasileiro-quebra- } \\
\text { recorde-mundial-de-salto-em- } \\
\text { cachoeira.html }\end{array}$ & $50 \mathrm{~min}$. \\
\hline 4 & $\begin{array}{l}\text { Introdução ao conceito de energia mecânica e } \\
\text { sua conservação: uma vez formalizados os } \\
\text { conceitos de energia cinética e energia potencial, } \\
\text { nesta etapa se objetivará evidenciar a relação entre } \\
\text { as duas e o conceito de energia mecânica. A etapa } \\
\text { também buscará permitir o reconhecimento da } \\
\text { conservação da energia mecânica. } \\
\text { A Etapa se dividirá em } 5 \text { momentos: } \\
\text { Momento } 1 \text { (5 min.) - comentários iniciais sobre a } \\
\text { relação os conceitos de energia cinética e mecânica } \\
\text { e questionamento sobre se há alguma relação entre } \\
\text { eles em um movimento. } \\
\text { Momento } 2 \text { (10 min.) - a partir de um vídeo que } \\
\text { indica um movimento e os gráficos de energia } \\
\text { associados, os alunos, reunidos em grupo com entre } \\
3 \text { e } 4 \text { integrantes, deverão buscar estabelecer } \\
\text { relações entre a energia cinética e a energia } \\
\text { potencial; } \\
\text { Momento } 3 \text { (5 min.) - discussão conjunta com a } \\
\text { turma, a partir das possibilidades que elencaram em } \\
\text { grupo, no momento } 2 \text {. A discussão deve ser }\end{array}$ & $\begin{array}{l}\text { Momento 2: } \\
\text { Vídeo audiodescrito com uma } \\
\text { animação representando o } \\
\text { movimento em uma montanha } \\
\text { russa, e com um indicador (objeto } \\
\text { irreal) das energias cinética, } \\
\text { potencial e mecânica, na forma de } \\
\text { barras (Vídeo 05); } \\
\text { Momentos 2 e 3: } \\
\text { Texto com questões de apoio às } \\
\text { discussões (Material 06). } \\
\text { Momento 4: } \\
\text { Texto explicativo sobre o } \\
\text { conceito de energia mecânica e de } \\
\text { conservação de energia mecânica } \\
\text { com exercícios conceituais e } \\
\text { algébricos, sendo um deles } \\
\text { baseado no movimento } \\
\text { apresentado no vídeo } 05\end{array}$ & $50 \mathrm{~min}$. \\
\hline
\end{tabular}




\begin{tabular}{|c|c|c|c|}
\hline & $\begin{array}{l}\text { encaminhada no sentido de reconhecer que a } \\
\text { relação entre energia potencial e energia cinética, } \\
\text { que sempre resultará em uma mesma quantidade de } \\
\text { "energia total"; } \\
\text { Momento } 4(25 \text { min. }) \text { - Formalização do conceito } \\
\text { de energia mecânica e da noção de conservação de } \\
\text { energia mecânica, e resolução de exercícios } \\
\text { algébricos. Parte dos exercícios deverão ser } \\
\text { realizados pelos alunos. } \\
\text { Momento } 5 \text { (5 min.) - discussão conjunta, } \\
\text { resumindo a relação entre energia cinética, } \\
\text { potencial e a conservação da energia mecânica, } \\
\text { destacando a relação matemática e os conceitos } \\
\text { físicos envolvidos. }\end{array}$ & $\begin{array}{l}\text { (Material 07) } \\
\text { Animação original (não editado e } \\
\text { sem audiodescrição) utilizada na } \\
\text { elaboração do vídeo: } \\
\text { Vídeo 05: } \\
\text { http://www.fisica-quimica- } \\
\text { secundaria- } \\
\text { bachillerato.es/animaciones-flash- } \\
\text { interactivas/mecanica_fuerzas_gr } \\
\text { avitacion_energia/energia_potenc } \\
\text { ial_cinetica_mecanica.htm }\end{array}$ & \\
\hline 5 & $\begin{array}{l}\text { Problematização do conceito de conservação de } \\
\text { energia mecânica a partir de situações reais } \\
\text { (forças conservativas e não conservativas): a } \\
\text { etapa objetivará evidenciar a relação entre } \\
\text { conservação de energia mecânica e a não atuação } \\
\text { de forças dissipativas. } \\
\text { A Etapa se dividirá em } 5 \text { momentos: } \\
\text { Momento } 1 \text { (5 min.) - comentários iniciais sobre a } \\
\text { relação à noção de conservação de energia } \\
\text { mecânica e questionamento sobre se há alguma } \\
\text { situação em que a energia mecânica não se } \\
\text { conservaria. } \\
\text { Momento } 2 \text { (10 min.) - a partir de um vídeo que } \\
\text { mostra uma queda livre em uma situação real, se } \\
\text { questiona o porquê da velocidade final alcançada } \\
\text { ser menor do que a velocidade que seria calculada } \\
\text { pela altura. Reunidos em grupo com entre } 3 \text { e } 4 \\
\text { integrantes, os alunos deverão buscar explicar o } \\
\text { problema colocado. Se espera que eles reconheçam } \\
\text { o atrito como aquilo que faz com que a velocidade } \\
\text { final seja menor do que a calculada; } \\
\text { Momento } 3 \text { (5 min.) - discussão conjunta com a } \\
\text { turma, a partir das possibilidades que elencaram em } \\
\text { grupo, no momento } 2 . \text { A discussão deve ser } \\
\text { encaminhada no sentido de reconhecer que havendo } \\
\text { atrito em um movimento, parte da energia iria se } \\
\text { "perder", não havendo a conservação da energia } \\
\text { mecânica (o que só ocorreria em situações ideais); } \\
\text { Momento } 4 \text { (20 min.) - Formalização do conceito } \\
\text { de força conservativa e força dissipativa (não } \\
\text { conservativa), e apresentação da ideia de } \\
\text { transformação de energia; } \\
\text { Momento } 5 \text { (10 min.) - discussão conjunta, } \\
\text { encerrando o tópico de conservação de energia } \\
\text { mecânica, permitindo aos alunos indicarem suas } \\
\text { compreensões. }\end{array}$ & $\begin{array}{l}\text { Momento 2: } \\
\text { Vídeo audiodescrito com um } \\
\text { movimento de queda livre com a } \\
\text { indicação do aumento da } \\
\text { velocidade na queda, da altura e } \\
\text { do tempo de queda. (Vídeo 06). } \\
\text { Obs.: O vídeo foi elaborado a } \\
\text { partir do mesmo vídeo original } \\
\text { utilizado para elaborar o vídeo } \\
\text { 04. A edição do vídeo 06, no } \\
\text { entanto, foca a velocidade final. } \\
\text { Momentos } 2 \text { e 3: } \\
\text { Texto com questões de apoio às } \\
\text { discussões (Material 08). } \\
\text { Momento 4: } \\
\text { Texto explicativo sobre sobre } \\
\text { forças conservativas e dissipativas } \\
\text { e sua relação com a conservação } \\
\text { de energia e com a transformação } \\
\text { de energia (Material 09). } \\
\text { Vídeo original (não editado e sem } \\
\text { audiodescrição): } \\
\text { Vídeo 06: } \\
\text { http://canaloff.globo.com/progra } \\
\text { mas/ultimas- } \\
\text { do/materias/brasileiro-quebra- } \\
\text { recorde-mundial-de-salto-em- } \\
\text { cachoeira.html }\end{array}$ & $50 \mathrm{~min}$. \\
\hline 6 & $\begin{array}{l}\text { Avaliação pontual: ainda que a avaliação se dê em } \\
\text { uma perspectiva formativa, ocorrendo ao longo de } \\
\text { todas as atividades da sequência, haverá um } \\
\text { momento pontual de avaliação. Assim, esta etapa } \\
\text { terá como objetivo servir de um momento adicional } \\
\text { de avaliação da aprendizagem, seja em um nível } \\
\text { conceitual relacionado a situações cotidianas, como } \\
\text { também em um nível representacional, envolvendo } \\
\text { resoluções algébricas. }\end{array}$ & $\begin{array}{l}\text { Avaliação pontual com questões } \\
\text { conceituais de resoluções de } \\
\text { problemas algébricos (Material } \\
\text { 10). }\end{array}$ & 50 min. \\
\hline & & Duração total: & $\begin{array}{l}5 \text { horas }(6 \\
\text { horas-aula } \\
\text { de } \quad 50 \\
\text { min.) }\end{array}$ \\
\hline
\end{tabular}




\section{Estrutura didática}

Conservação da Energia mecânica

(Sequência baseada no uso de vídeos audiodescritos)

\begin{abstract}
Conhecimento Físico
Orientação global sobre energia (Etapa 1)

que envolverá o questionamento "em um movimento, onde há energia?" (Etapa 2, momento 2)
\end{abstract}

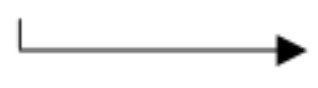

que culminará com uma pergunta como "Entre dois carros correndo, para qual haverá mais energia relacionada ao movimento?" (Etapa 2, momento 3)

levando-os a reconhecer a relação entre velocidade e energia, e à formalização do conceito de energia cinética (Etapa 2, momentos 4, 5 e 6)

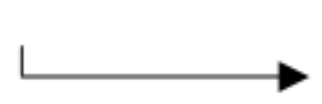

Motivo

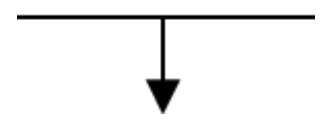

o que deve resultar numa sensação de que é algo que pode ser estudado (Etapa 1)

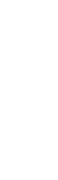


a partir das quais deve

resultar um novo critério para definir o potencial de um corpo em iniciar um movimento (Etapa 3, momento 3)

que levará ao reconhecimento do papel da altura do corpo no potencial em desenvolver o movimento (Etapa 3 , momento 3 )

que culminará com o conceito de energia potencial e sua formalização (Etapa 3, momentos 4 e 5)

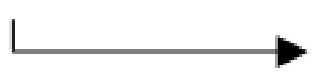

que deve levar a um questionamento sobre alguma relação entre a energia potencial e a energia mecânica (Etapa 4, momentos 2 e 3 )

levando ao conceito de Conservação de energia mecânica (Etapa 4, momentos 4 e 5)

que levará a reconhecer que a conservação de energia mecânica se dá em situações ideais (Etapa 5, momento 3)

sem a atuação de forças dissipativas, podendo existir somente forças conservativas (Etapa 5, momento 3).

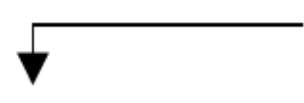

o qual deve ser contrastado o qual deve ser associado com a energia cinética (Etapa 4, momento 1)

a partir de uma situação típica como o do movimento em uma montanha russa (Etapa 4, momento 2 - vídeo 05) com situações reais do cotidiano (Etapa 5 , momentos 1 e 2)

,

\footnotetext{
que deve ser formalizado em

função do conhecimento até então

tratado e ancorado em elementos
}

RIAEE - Revista Ibero-Americana de Estudos em Educação, Araraquara, v. 13, n. 03, p. 1164-1186, jul./set., 2018. E-ISSN:1982-5587. 
perceptíveis (Etapa 5, momento 4)

o que ocorrerá a partir de uma discussão sobre força gravitacional como uma força conservativa e força de atrito como uma força dissipativa (Etapa 5, momento 4)

permitindo reconhecer a transformação da energia mecânica em outras formas de energia, inclusive aquelas surgidas no início da discussão (Etapa 5, momento 4) levando a um ponto de fechamento em que podemos perguntar "o que nós fizemos?" (Etapa 5, momento 5; Etapa 6)

levando ao encerramento da discussão sobre o tópico de conservação de energia mecânica e transformação de energia (Etapa 5, momento 5; Etapa 6). 